\title{
Interim Findings from the Uni Connect Raising Higher Education Aspirations Evaluation in Lincolnshire
}

\author{
Anthea Rose* and Lucy Mallinson \\ Lincoln Higher Education Research Institute (LHERI), University of Lincoln, Brayford Pool, Lincoln, \\ Lincolnshire. LN6 7TS
}

${ }^{*}$ Corresponding author: arose@lincoln.ac.uk

Keywords: Uni Connect, Raising aspirations, Outreach activities, Covid-19

\begin{abstract}
This short article summarises the evaluation findings from the end of Year 1 Phase 2 Uni Connect Raising Higher Education Aspirations project in Lincolnshire. This national initiative, funded by the Office for Students, delivers targeted Higher Education outreach activities to young people in Years 9 to 13 in areas where the Higher Education participation of young people is much lower than expected based on GCSE-level attainment. These areas often coincide with where universities focus their widening participation efforts to help them meet their Access and Participation Plans. In Lincolnshire the project is managed and delivered by LiNCHigher, one of 29 local learning partnerships involved in the project nationally. The data were collected between March and July 2020 during the Covid-19 national lockdown when all schools were closed and draws primarily on data collected from six case study schools. Evaluation activity comprised an online student activity survey, semi-structured interviews with School and College Leads, LiNCHigher Area Engagement Officers and two student focus groups, conducted just prior to lockdown in early March. The evaluation found that, prior to Covid-19, interventions were beginning to have a positive impact on the Higher Education aspirations of all students and that schools both welcomed and valued the initiative highly. The evaluation report made several recommendations, including ensuring workshops are more interactive.
\end{abstract}

\section{Introduction}

This article presents the interim evaluation findings from the end of Year 1 Phase 2 Lincolnshire Uni Connect Raising Higher Education Aspirations project. Funded by the Office for Students (OfS) and managed locally by LiNCHigher, a consortia partnership, the project delivers targeted Higher Education (HE) transitional outreach activities to young people in Years 9 to 13 in areas of England where the HE participation of young people is both low and much lower than expected based on GCSE-level attainment. Across England, some 997 wards have been identified as falling into this category, including 24 wards in Lincolnshire. The initiative is specifically targeted at those from backgrounds that strongly indicate they are significantly less likely to progress onto HE, i.e. non-traditional students. These same students are often the focus of universities' Access and Participation Plans. There are 28 other local Uni Connect partnerships in England involved in the project, each consisting primarily of universities and colleges.

The evaluation component of the Lincolnshire programme is being carried out by a small team of researchers from the Lincoln Higher Education Research Institute (LHERI), at the University of Lincoln.

\section{Review of literature}

A comprehensive review of literature relevant to the Uni Connect project covering key areas 


\begin{tabular}{|c|c|c|c|}
\hline School & Area & $\%$ Uni Connect & Size / Students on role \\
\hline School A & East Coast & $64 \%$ & Large $~ 950$ \\
\hline School B & Boston & $50 \%$ & Large $\sim 1165$ \\
\hline School C & Grantham & $61 \%$ & Small $~ 235$ \\
\hline School D & South Holland & $52 \%$ & Medium 700 \\
\hline School E & East Lindsay & $19 \%$ & Medium $~ 700$ \\
\hline School F & City & $37 \%$ & Large 920 \\
\hline
\end{tabular}

Table 1 Key characteristics of the case study schools

such as making informed post-18 choices, parental influence, the university application process, and the impact of outreach activities, as well as the theoretical approach employed by the project, has already been undertaken and published (Rose \& Mallinson, 2020). Therefore, this section provides a brief overview of the policy context in which Uni Connect sits.

Over the last 20 years the widening access to $\mathrm{HE}$ agenda has resulted in more non-traditional young people entering university education at the age of 18 than ever before (Wyness, 2017 \& O'Sullivan et al., 2019). According to Holton (2018: 557), non-traditional students are defined as, 'first-generation university attendees from working-class or minority backgrounds', whose knowledge of HE is limited. These learners are sometimes referred to as disadvantaged (Wyness, 2017) or firstgeneration (Thompson, 2019; Roksa \& Silver, 2019) students. In the context of the project under discussion here, these learners are referred to as Uni Connect students.

Despite the increase in uptake of HE in recent years, there remains a significant gap between the percentage of traditional and nontraditional students accessing university education (OfS, 2019a; Social Mobility Commission 2019) and in some areas, such as access to the top universities, the gap has actually widened (Education Policy Institute, 2019). To help address this issue, in 2015 the Government, under its social mobility programme (BIS, 2015), extended its widening participation agenda considerably. As a result, in January 2017 Uni Connect (originally known as the National Collaborative Outreach Programme or NCOP) was launched. Funded by the OfS (then HEFCE), Phase 1 ran until July 2019; Phase 2 commenced in August 2019 and will finish in July 2021 (see OfS, 2019b). This short article presents the emergent findings from the evaluation at the end of Year 1 Phase 2.

\section{Methodology}

The full report draws on evaluation activities conducted between March and July 2020, during the Covid-19 national lockdown when all schools in England were closed, or about to close. The data were collected from six case study schools and two colleges receiving targeted support from LiNCHigher as part of the Uni Connect project. Spread throughout the county, each had agreed at the start of the academic year (September 2019), to take part in the evaluation.

For the purpose of this article the names of participating schools have been anonymised and are referred to here as School A, B, C, D, $E$ and $F$. Table1 summarises the key characteristics of the six case study schools and where in the county they are located.

Evaluation data were collected through an online student activity survey, student focus groups and interviews with LiNCHigher Area Engagement Officers (AEOs), case study 


\section{NERUPI Framework Five Overarching Aims (www.nerupi.co.uk)}

NERUPI Category A: Know Develop students' knowledge and awareness of the benefits of Higher Education and graduate employment

\section{NERUPI Category B: Choose}

Develop student's capacity to navigate Higher Education and graduate employment

\begin{tabular}{|l|l|}
\hline $\begin{array}{l}\text { NERUPI Category C: } \\
\text { Become }\end{array}$ & $\begin{array}{l}\text { Develop students' confidence and resilience in Higher } \\
\text { Education and graduate employment }\end{array}$ \\
\hline $\begin{array}{l}\text { NERUPI Category D: } \\
\text { Practice }\end{array}$ & $\begin{array}{l}\text { Develop students' skills and capacity for student and career } \\
\text { success }\end{array}$ \\
\hline $\begin{array}{l}\text { NERUPI Category E: } \\
\text { Understand }\end{array}$ & $\begin{array}{l}\text { Develop understanding through contextualised subject } \\
\text { knowledge and attainment raising }\end{array}$ \\
\hline
\end{tabular}

Table 2 NERUPI Framework

School and College Leads. AEOs work closely with several schools across the county, usually within a specific area. Each school involved in the project has an allocated AEO who works closely with the school to raise the higher education aspirations of their students.

The student activity survey was administered online via a link emailed to students by the case study School Leads. The survey asked students to rate the outreach activities they liked most and least. A range of outreach activities were evaluated including; campus visits, career fairs, motivational speakers, a number of different finance and revision/study skill workshops and National Enterprise Challenge days. Students were asked only about activities that took place in their school and for their year group between September 2019 and March 2020. The impact of all activities that students engaged with was assessed against the Network for Evaluating and Researching University Participation Interventions (NERUPI) Framework, the aims of which are detailed in table 2.

A total of 853 student survey responses were received. However, after data cleaning this reduced by $21 \%$ to 672 valid responses. A total of $37 \%$ of responses came from Uni Connect students and $63 \%$ from non-Uni Connect students. Some $54 \%$ of responses were from female and $39 \%$ from male students.
The number of student responses varied across case study schools and year groups as set out in Table 3.

Semi-structured interviews were conducted with six case study School and two College Leads as well as the four AEOs in-post and active at the time of the interviews (June 2020). All interviews were conducted remotely either by telephone or video call, audio recorded and later transcribed.

At the beginning of March 2020, just prior to the national lockdown, two student focus groups were conducted at case study school C. Each focus group consisted of six students, one comprising Uni Connect students and one nonUni Connect students.

\section{Limitations of the evaluation design and subsequent impact evidence}

Due to Covid-19, and the subsequent closure of all UK schools in March 2020, it was not possible to carry out the full range of planned Phase 2 Year 1 evaluation activities, the majority of which had been scheduled for the summer term (specifically student focus groups). Furthermore, the number of interventions students received during the year was reduced to just two terms of activities. Therefore, the student activity survey only covered outreach activity students participated 


\begin{tabular}{|l|c|c|c|c|c|c|}
\hline School & Year 9 & Year 10 & Year 11 & Year 12 & Year 13 & Total \\
\hline School A & 61 & 44 & 27 & 33 & 14 & 179 \\
\hline School B & 57 & 89 & 37 & N/A & N/A & 183 \\
\hline School C & 17 & 28 & 7 & N/A & N/A & 52 \\
\hline School D & 32 & 10 & 14 & N/A & N/A & 56 \\
\hline School E & 42 & 35 & 9 & N/A & N/A & 86 \\
\hline School F & 0 & 43 & 38 & 21 & 14 & 116 \\
\hline Total & 209 & 249 & 132 & 54 & 28 & 672 \\
\hline
\end{tabular}

Table 1 Student activity survey responses by school and year group

in prior to the lockdown (i.e. between September 2019 and early March 2020) rather than a full academic year, as originally planned. In the absence of being able to talk to the students directly, some open text questions were added to the survey to try to capture the student voice.

Finally, the response rate to the activity survey was lower than originally anticipated since students were entrusted to complete the survey from home, rather than in a school setting. The number of Uni Connect students that participated in the survey was lower than expected and disproportionate to the actual number that attend the six case study schools. The completion rate for Uni Connect students was $37 \%$ compared to $47 \%$ that attend the six case study schools.

\section{Interim findings}

This section summaries the interim findings from the evaluation report at the end of the first year. The full report, which includes a detailed breakdown of the data provided by the student activity survey, can be found at Year 1 Phase 2 Uni Connect evaluation report to LiNCHigher (cpb-eu-w2.wpmucdn.com).

The results of the online student activity survey showed medium-term impact on student HE aspirations for several of the outreach activities, specifically, the National Enterprise Challenge, campus visits, career fairs and revision sessions. However, it also highlighted that students do not necessarily have to enjoy a session for it to be beneficial. For example, a total of 136 students across the six case study schools took part in an exam or revision workshop. Almost half (49\%) said they enjoyed the sessions the least of all the activities they had taken part in. However 59\% either agreed or strongly agreed that the workshop had improved their revision or study skills.

Overall, the survey showed that students wanted more time with most of the activities (e.g. campus visits, careers fairs), want them to be more fun (revisions workshops, Finance4Kids), more interactive (motivational speakers, workshops) and linked more closely to the curriculum and their work in class (English travel writing workshop, Finance4Kids).

These findings were supported by the feedback gathered from the two focus groups that took place at case study School $C$ in early March. The focus groups, one consisting of Uni Connect students and one of non-Uni Connect students, explored the views of Year 9 students that had attended a one-hour travel writing workshop. Whilst the non-Uni Connect students had found it easier to follow than their Uni Connect counterparts, none of the students had particularly enjoyed the workshop. They felt the workshop leader was difficult to understand, her language was too complex, and the session had little or no connection with what they had been learning in class. One Uni Connect student described the session as "confusing", another commented: "in my opinion, it didn't help us at all. I'm not saying it wasn't good, but it didn't help us with anything we were doing in lessons". The other students in the group agreed this was the case. Other comments from the Uni Connect students included: 
It showed us what lectures are going to be like if we ever go to university, and how you have to listen to them and take notes.

A lot of us were saying, "We don't know what that means". It was just so different to what we're doing in lessons and so complex, it was, like, everything she was saying, we needed to have it explained more to us.

When asked what they would have liked in the session, one student commented:

Something a little less grown-up, something less complex, because it was quite complex language in terms of the writing...

The Uni Connect students would have liked the session to have been at a lower level, more interactive and activity-based: "so it's not just constant talking, talking".

The non-Uni Connect students had mixed views about the session with one describing it as "good", one as "quite interesting" and another as "quite insightful", even if they also felt it had "dragged on a bit", was "a bit boring" and "dull". These students felt the session had more connection to their writing in class and provided useful tips and strategies on how to approach their own writing, including the use of language devices and paragraphs. One student commented: "it helped with how to structure it properly. Instead of just writing something down like a story, it told us how to do it in, like, a non-fictional way". However, the non-Uni Connect students also wanted the session to be more interactive with one student commenting:

It could be more fun, like, games, and all that. I think instead of, like, just talking and discussion, to have, like, a worksheet to work through, and stuff like that.

These students would also have liked an opportunity during the session to have developed their own travel writing ideas.
Students responding to the activity survey also noted when presenters were not enthusiastic or did not appear to engage with the students as they expected them to. Feedback from students at school A illustrated how one motivational speaker was particularly poorly received with one student commenting that "she was boring and made me feel inferior", another student said: "she was very selforientated...we mainly heard about her and not what we could do". Therefore, the impact of motivational speakers varied depending on who the speaker was and what they were trying to inspire in the students.

In terms of improving specific activities, students would have liked campus visits to be longer and include opportunities to visit and experience more of the facilities, such as science labs and seminar rooms. At career fairs students would have liked more stands with a greater variety of careers and employers to be represented. Students would have liked revision workshops to provide them with new ideas of how to approach their revision. Whilst popular, the main issue students had with events such as the National Enterprise Challenge was presenting in front of large groups of other students.

The results of the activity survey did not appear to show any overall difference in impact between Uni Connect and non-Uni Connect students. However, some differences were observed at an activity or year group level. For example, the Grenade Challenge (National Enterprise Challenge) had a bigger impact on students in Year 10 than in Year 9 with the difference most marked for improving confidence (NERUPI category C) or My Perfect University, a workshop where groups of students design all aspects of a university, had the biggest impact on Uni Connect students, particularly in enabling them to know what to look for when choosing a university (NERUPI category B).

Pre-Covid-19, School and College Leads felt they had made good progress raising the aspirations of their students to progress onto $\mathrm{HE}$ or higher-level apprenticeships and this was borne out by the results of the student activity survey. The School C Lead commented that he had "really noticed a turning point" following their last College visit with Year 9 
students, describing the impact as "powerful". As a result of the visit teachers had been able to start conversations with students about what their next steps might be. He further commented: "it was almost a culture shift". At case study school D both the AEO and the School Lead reported a shift in culture at the school as a result of outreach interventions. The School Lead commented: "we have found there is a difference. Students are talking about university more. They're talking about looking at higher level apprenticeships". Furthermore, the AEO had noticed that staff at the school were "much more engaged in the idea of careers education and embedding careers into their normal teaching". Together this anecdotal evidence also indicates a cultural shift in this school.

The relationship between School Leads and LiNCHigher, especially their designated AEO, was reported to be strong, productive, reliable and open. Communication generally worked well, in both directions, and School Leads undoubtedly valued the work of LiNCHigher in raising the aspirations of all their students, especially in the area of HE progression. Relationships were strongest in the schools where the AEO had remained the same person throughout. Comments from School Leads included:

\section{I can't thank LiNCHigher enough, I think} we work really well with them.

Everything that we have from them is really well received. (School A)

We have a good working relationship and there are lots of things that we just wouldn't be able to do without them.

(School B)

When we email, there's always a response within a few days. If they're organising a bus, they organise the bus.

There's always communication.

$$
\text { (School A) }
$$

However, the evaluation found that the relationship between the colleges and the Partnership could be stronger and required further developing for the programme to have an impact on their Level 2 and 3 students in the second year of Phase 2. Ideally the colleges would like to see the outreach activities for these students start much earlier in the college year than they have previously, if possible, by the end of September.

Finally, the evaluation found student ambassadors were underused. Using student ambassadors effectively was reported by the AEOs to be challenging. Whilst they were viewed as a valuable asset in being able to connect with the students and share their experiences, student ambassadors had mainly been used for large one-day events such as the WoW (World of Work) Festival and the National Enterprise Challenge days. However, they had not been utilised as much as the AEOs had hoped. One of the main reasons for this was seen to be the logistics of getting student ambassadors to schools, which usually meant them using public transport to reach schools in rural areas.

Overall, the work of LiNCHigher and the outreach activities they fund were well received and valued by the School and College Leads. There was a particularly good working relationship between AEOs and School Leads. Anecdotally, interventions were starting to have a positive impact on the HE aspirations of all students prior to Covid-19, and this was evidenced through the online activity survey data. In some schools the impact was reported to be school-wide, resulting in a cultural shift in attitude towards HE.

\section{Recommendations for Phase 2 Year 2 (2020-21)}

Based on the evidence in the report, the following recommendations were made. The partnership should:

- Endeavour to keep AEOs with their allocated schools throughout the school year to ensure stability. This will improve the potential for the programme to have a positive, longer-term impact on student HE aspirations.

- Ensure workshops are interactive, engaging and set at the level of the students they are delivering to.

- Select motivational speakers carefully.

- Consider placing a LiNCHigher member of staff on-site in each of the colleges, at least one day a week.

- Begin working with colleges earlier in the school year.

- Reconceptualise the role of student ambassadors. 


\section{Concluding remarks}

Whilst the project has been well received by the case study schools and colleges and there was evidence of impact in relation to raising students' HE aspirations, there remains much work to do in the second, and final year, of the project. This work has been made more challenging for both the Partnership and the schools and colleges, due to the ongoing Covid-19 situation. Potential challenges highlighted by the School and College Leads and the AEOs, at the time of the interviews (June 2020), included: the limiting of student access to ICT equipment such as laptops; reengaging and motivating students, especially Year 10s; the delivery of meaningful outreach activities virtually; LiNCHigher maintaining a good relationship with all their schools; and encouraging School Leads to continue to keep raising $\mathrm{HE}$ aspirations high on the agenda of School Leadership Teams.

\section{References}

BIS (Department for Business, Innovation and Skills) (2015) Fulfilling our Potential: Teaching Excellence, Social Mobility and Student Choice. London: BIS.

https://assets.publishing.service.gov.uk/governm ent/uploads/system/uploads/attachment data/fil e/474227/BIS-15-623-fulfilling-our-potentialteaching-excellence-social-mobility-and-studentchoice.pdf

Education Policy Institute (2019) Geographical Analysis Pack Education in England: Annual Report 2019, Education Policy Institute and Fair Education Alliance https://epi.org.uk/wpcontent/uploads/2018/07/EPI-Annual-Report2018-Geographical-Analysis-Pack.pdf

Holton, M. (2018) Traditional or non-traditional students: Incorporating UK students' living arrangements into decisions about going to university. Journal of Further and Higher Education. 42(4), 556-569. DOI: 10.1080/0309877X.2017.1301408

OfS (Office for Students) (2019a) Guide to the access and participation data resources. https://www.officeforstudents.org.uk/data-andanalysis/access-and-participation-datadashboard/guide-to-the-access-andparticipation-data-resources/findings-from-thedatal
OfS (Office for Students) (2019b) National Collaborative Outreach Programme. London: OfS.

https://www.officeforstudents.org.uk/advice-andguidance/promoting-equalopportunities/national-collaborative-outreachprogramme-ncop/

O'Sullivan, K., Robson, J. \& Winters, N. (2019) 'I feel like I have a disadvantage': How socioeconomically disadvantaged students make the decision to study at a prestigious university. Studies in Higher Education, 44(9), 1676-1690. DOI: 10.1080/03075079.2018.1460591

Roksa, J. \& Silver, B.R. (2019) "Do-It-Yourself" university: Institutional and family support in the transition out of College. The Review of Higher Education, 42(3), 1051-1071. DOI: 10.1353/rhe.2019.0029

Rose. A, \& Mallinson, L. (2020) Raising aspirations for non-traditional students through Higher Education outreach activities: A review of literature relevant to the Uni Connect programme, IMPact Journal, University of Lincoln, 3(1), 1-22. https://cpb-euw2.wpmucdn.com/blogs.lincoln.ac.uk/dist/c/83 16/files/2020/10/Rose-and-Mallinson-UniConnect-2020.pdf

Social Mobility Commission (2019) State of the Nation 2018-19: Social mobility in Great Britain. London: Her Majesty's Stationery Office.

https://assets.publishing.service.gov.uk/governm ent/uploads/system/uploads/attachment data/fil e/798404/SMC State of the Nation Report 2 018-19.pdf

Thompson, D.W. (2019) Aspirations and ambiguities: The need for focused IAG for school pupils considering progression to higher education (HE). Journal of Further and Higher Education, 1-15.

https://doi.org/10.1080/0309877X.2019.16160 $\underline{81}$

Wyness, G. (2017) The rules of the game: Disadvantaged students and the admissions process. London: The Sutton Trust. https://www.suttontrust.com/wpcontent/uploads/2017/12/Rules-of-the-Game.pdf 